ils), and is written so that you can almost smell the smoke of the camp-fire, the descriptions of occasional trips to town are just as evocative of Africa. We meet a rich array of ramshackle bars with ramshackle customers, we play plenty of darts and hear many a comic or curious yarn.

Perhaps the best is the one about the Afrikaner who, at a time of severe floods, managed one moonless night to drive across a bridge that not only had no handrail but was under two feet of water. On being asked how he managed this, he replied: "What bridge?"

Keith Cox is in the Department of Earth Sciences, University of Oxford, Parks Road, Oxford OX1 $3 L Y, U K$.

\section{Fringe maths}

\section{Fermat's Last Theorem: The Story of a Riddle that Confounded the World's Greatest Minds for $\mathbf{3 5 8}$ Years}

by Simon Singh

Fourth Estate: 1997. Pp. 362. £12.99

\section{Keith Devlin}

On 23 June 1993, the world of mathematics was electrified by the news that the British mathematician Andrew Wiles had proved Fermat's last theorem, a problem in number theory that had resisted numerous attempts at solution for more than 350 years.

Within a few months of that dramatic announcement, an error had been found in the proof. Although everyone agreed that Wiles had produced some of the most remarkable mathematics of this century, he had not, as he had first thought, solved what was almost certainly the most famous open problem in mathematics.

Then, in October 1994, Wiles announced that he had corrected the mistake. This time, the experts agreed that his proof was correct. The complete argument was published in Annals of Mathematics in May 1995.

That, in a nutshell, is the story. John Lynch, editor of the BBC 'Horizon' series, sensed a good television documentary and was on to the story from the first announcement. As his co-producer and director, Lynch chose Simon Singh, a physics $\mathrm{PhD}$ who had worked in television for five years. The resulting programme was broadcast in 1996. This book is a spin-off from the programme. It comes close on the heels of another book of the same title, by Amir Aczel, which was reviewed in Nature last October $(383,774 ;$ 1996). That review applies virtually word for word to the Singh book.

Both books adopt the same overall approach. They offer plenty of discussion of the early history of Fermat's last theorem, a selection of mathematics' most durable and

oft-repeated anecdotes and examples, many of them having little connection to the theorem (such as sphere packing, the fourcolour theorem, the Galois saga), capped off with the briefest of thumbnail sketches of Wiles's proof.

The similarity is an inevitable consequence of the difficulty facing anyone who sets out to write a popular account of Wiles's solution to the problem of the theorem. The problem itself is easily understood, and the human drama that surrounds it has all the elements of good drama, from the problem's origin right up to the final acknowledgment that it had indeed been solved. But the solution is something else. There are probably only a dozen mathematicians in the world who are sufficiently knowledgeable to follow Wiles's proof fully, and maybe a few hundred who can, with difficulty, struggle through it.

Fermat's claim was that for no whole number $n$ greater than 2 can the equation $x^{n}+y^{n}=z^{n}$ have any whole number solutions for $x, y, z$ (except where one of the numbers is zero).

Wiles's proof involves building a bridge to connect two areas of deep mathematics that had hitherto been regarded as entirely separate, the theory of elliptic functions and the theory of modular forms. As long ago as 1954, two Japanese mathematicians, Yutaka Taniyama and Goro Shimura, had suggested that these two areas were connected. But, although over the years an increasing number of mathematicians had come to accept the possible truth of the Taniyama-Shimura

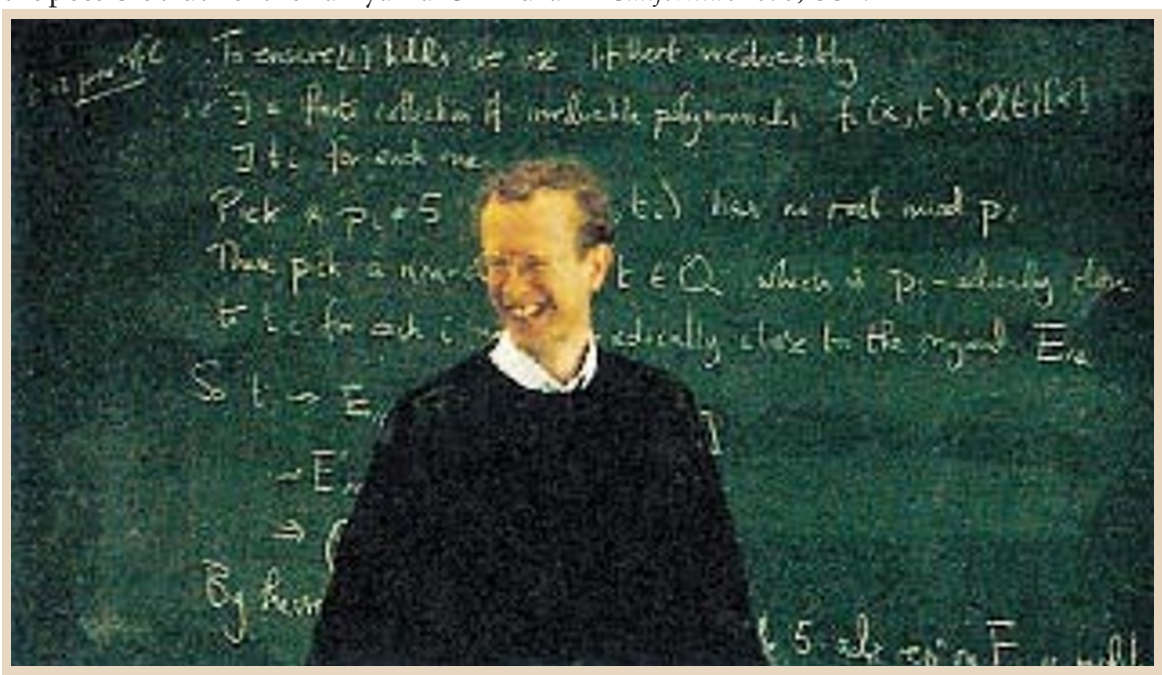

\title{
Money in the equation
}

Wiles's proof of Fermat's last theorem is also now described in the paperback edition of Keith Devlin's Mathematics: The Science of Patterns (W. H. Freeman/Scientific American Library, $\$ 19.95, \mathfrak{E} 14.95)$. The book was originally published in 1994, shortly before the proof's discovery, and was reviewed in Nature 373, 206 (1995). As Devlin points out, the offer of various awards to the first person to find a conjecture, most thought that a proof was many decades away.

In 1986, Ken Ribet proved the surprising result that Fermat's last theorem is a consequence of the conjecture, providing Wiles with a possible way to attack a problem that had fascinated him since childhood.

By proving a special case of the Taniyama-Shimura conjecture, Wiles not only proved Fermat's last theorem, he opened the doors wide to an entirely new era in number theory. His proof was both an end to a 350year-old riddle and the beginning of an era in which we will learn much more about those oh-so-familiar counting numbers that lie at the heart of mathematics.

For a would-be author of a book that sets out to explain the story of the last theorem, the only viable approach is to provide mathematical detail around the edges, where its only function is to put some mathematical content between the book's covers, and to concentrate on the human drama when it is time to describe the problem's final resolution. Although I think Singh's book would have been better had he included less of the peripheral 'popular mathematics' dressing, his treatment of the human drama is well done, and as a result the book succeeds.

Non-mathematicians should get something of the flavour of the way mathematicians work, while mathematicians will enjoy learning some of the human details surrounding the eventual solution.

Keith Devlin is at Saint Mary's College of California, Moraga, California 94575, USA. 